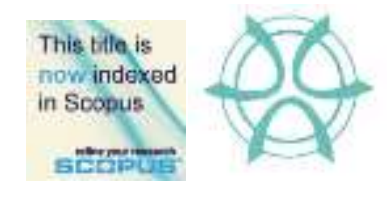

PLANNING MALAYSIA:

Journal of the Malaysian Institute of Planners

Volume XIII (2015), Page 37 - 50

\title{
THERMAL COMFORT AND ENERGY SOLUTIONS FOR A BETTER RESIDENTIAL ENVIRONMENT IN MALAYSIA
}

\author{
${ }^{1}$ Noor Aziah Mohd Ariffin \\ Kulliyyah of Architecture and Environmental Design \\ INTERNATIONAL ISLAMIC UNIVERSITY MALAYSIA
}

\begin{abstract}
In hot-humid Malaysia, there are around five million units of housing. Among these, the medium-density terraced are the most built. However, little emphasis was given to designing for thermal comfort and energy efficiency. Consequently, air-conditioning is ubiquitous with ever-rising residential energy consumption. This paper studied passive design systems to improve living conditions and conserve energy through orientation and insulation parameters for terraced housing. Utilizing a triangulation of methods to correlate between thermal comfort and energy performance, findings from the questionnaire survey, data monitoring and computer simulation contended that with the passive design strategies minimum thermal comfort is attainable and energy savings predicted.
\end{abstract}

Keyword: terraced houses; passive design; thermal comfort; energy savings

\section{INTRODUCTION}

Malaysia has experienced rapid economic development and social transformation in the past four decades, characterized by rapid urbanization due to substantial population growth, which has in turn resulted in intensification in the demand for housing (Mohd Razali, 2002). Due to this phenomenon, many houses were urgently built, frequently being planned and designed without much forethought about the attributes of the local climate. As a consequence, these newly built houses are uncomfortable and hot (Davis, Shanmugavelu \& Adam, 1997) and this has resulted in an increased use of energy for cooling (Byrd 2006), which has contributed to the effects of climate change.

${ }^{1}$ Lecturer at Department of Architecture, Kulliyyah of Architecture and Environmental Design, IIUM Email: nooraziah@iium.edu.my 
Noor Aziah Mohd Ariffin

Thermal Comfort And Energy Solutions For A Better Residential Environment In Malaysia

Housing stock in Malaysia has increased and the latest residential property stock report for the first quarter (Q1) in 2014 puts the housing stock in Malaysia of all residential types at 4,746,184 units (NAPIC, 2014). Terraced house, consisting of single, double and even triple-storey houses, constitutes the largest type division at $41 \%$ or $1,923,802$ units of the national existing housing stock and represents the most popular housing type (Phoon, 2004). With the rise of the housing stock the use of electrical energy in the residential sector inevitably increases as well. According to the national energy data available, energy consumption in the residential sector has increased from $17.5 \%$ in 2002 to $21 \%$ in 2006 (Energy Commission Malaysia, 2005). This increment is interlinked with the rise in the progressive efforts of the nation to develop which resulted in the emergence of the middle-class population in Malaysia (Torii, 2003), which is in turn, partly responsible for steering the trend toward an energy-intense lifestyle.

\section{AIM AND OBJECTIVES}

The aim of this study is to investigate the potential passive design strategies in typical medium density terraced houses in Malaysia in order to achieve thermal comfort for the occupants and be energy efficient as well. The paper seeks to ascertain the means by which energy consumption for cooling purposes in medium density terraced houses in Malaysia can be minimized. Given the nature of the climate, which is mostly hot and outside the comfort range throughout the year, it considers those design factors such as orientation and other design improvements to try to find alternate design strategies that will reduce residential energy consumption while maintaining thermal comfort. The information gathered will become the basis for all involved in the designing of the residential sector (especially for terraced houses) in Malaysia to rethink of a new design paradigm for the conventional approach of house building with particular attention to medium density construction.

\section{BACKGROUND}

Malaysia is situated in the hot and humid equatorial region, where daily temperatures between $24^{\circ}-34^{\circ} \mathrm{C}$ are common. It is slightly cooler when it rains. Coupled with high humidity (averaging more than $80 \%$ most of the year) and compounded by a lack of wind flow, thermal comfort is difficult to attain naturally. As a consequence, artificial ventilation is required almost all the time because internal conditions become hot and uncomfortable, not only during the day, but also well into the night. Studies have found that nighttime internal temperatures in terraced houses usually remain on the upper limit of the thermal comfort zone until the early hours of the morning. This necessitates some form of artificial cooling and of late the use of air conditioning has become ubiquitous. Due to this, the use of electrical energy in the residential sector has increased tremendously in recent years. On top of that, ownership of air conditioner units 
PLANNING MALAYSIA

Journal of the Malaysia Institute of Planners (2015)

in 2005 had increased by $32 \%$ since 1999 and this is predicted to increase to almost $60 \%$ by the year 2015 if the present trend persists (Saidur et. al., 2007). As a consequence, energy demand will increase as well. The availability of cheap and affordable air conditioner units due to the boom in the industry has made their purchase easier.

\section{LITERATURE REVIEW}

\section{Housing Situation}

Terraced house designs were introduced in Malaysia (then Malaya) around the beginning of the twentieth century during the early years of British colonial rule. Based on the British terraced home designs, the houses usually have only two elevations: the front and back. The living quarters and the main bedroom are located at the front of the house, and the kitchen and other bedrooms are at the back. Mass contemporary and intrinsic terraced houses have been built since the late 1960's, but the design of the buildings has not evolved much since its predecessor (Figure 1).

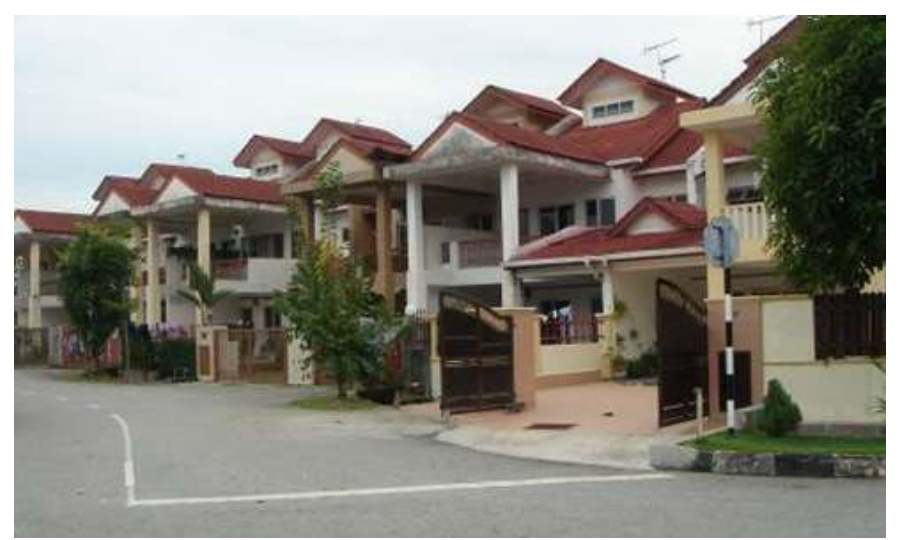

Figure 1: Contemporary terraced houses

Studies have established that the terraced houses designs are not climatically appropriate for hot humid climate of Malaysia. Davis et. al. (1997) and Noor Aziah (2008) established that most concrete terraced houses in Malaysia are comfortable for only a few hours a day, if at all, compared to the natural environment. The works of Al-Obaidi and Woods (2006) and Nugroho, Mohd Hamdan and Ossen (2007) also confirmed the poor thermal conditions of the present terraced house designs. One of the common design flaws being the inappropriate building orientation amplified the negative thermal effects even more. The use of passive design features, such as insulation in the roofs or walls or improvement in glazing, is seen as superfluous, costly and unnecessary. 
Noor Aziah Mohd Ariffin

Thermal Comfort And Energy Solutions For A Better Residential Environment In Malaysia

\section{Energy Situation}

In Malaysia, buildings consume about 22 percent of total energy used with the residential sector using more than half that (Byrd, 2006). It also responsible for contributing about $7 \%$ greenhouse gas emissions. The trend is ever increasing and can be attributed to the country's projected high growth in economic activities and income. In reality, it may also be due to inefficiencies in the operation and the inherent design-related inefficiencies of the building sector (Balce \& Soriano, 1999). Lack of regulations pertaining to energy efficiency of buildings in the earlier years can also be a factor. The re-introduction of the Malaysian Code of Practice on Energy Efficiency and Use of Renewable Energy for Non-Residential Buildings in 2001 (Department of Standards Malaysia, 2001) marked a major move by the country towards controlling energy use in commercial buildings. In 2009, a new Green Building Index (Green Building Index, 2009) - energy-rating tool was introduced to the residential sector in the tropical context to address the basic issues and problems of energy use in the residential sector.

\section{Thermal Comfort Studies}

Comfort zones delineated in ASHRAE Standard 55-2010 (2010) for summer conditions (similar to Malaysian climate) put it at having a neutrality value of $24.5^{\circ} \mathrm{C}$ with a comfort range between $23.0-26.0^{\circ} \mathrm{C}$, airflow at $0.25 \mathrm{~m} / \mathrm{s}$ and at $50 \%$ humidity. The activity level is $0.5 \mathrm{met}$, for mainly sedentary work with Clo value of 0.5 (light slacks with short sleeves shirt or blouse). The standards based on theoretical analyses of human heat exchange in climate chambers using Fanger's (1972) predicted mean vote (PMV) formula, which predicts a numerical value for the mean subjective response to the thermal environment from a comfort scale. These standards however elicit a very narrow zone of occupant comfort; that is achieved through mechanical means with cost implications. However, researchers for the hot and humid conditions have debated these figures vigorously. Many studies have ascertained that these figures are not representative for naturally ventilated buildings and also for buildings with multivariability controlled options. Nicol (2002) showed that ISO 7730 overestimates the occupant response on the ASHRAE PMV scale at high temperatures where subjects in field surveys in the tropics find higher temperatures as being comfortable than prescribed in the standard. Many researchers also argue that the standards "ignore importantly contextual differences that can attenuate responses to a given set of thermal conditions" (deDear, Brager \& Cooper, 1997, pp: 7). The relevance of applying the standardized comfort zones for naturally ventilated buildings is questionable. Givoni (1994) acknowledged this matter by revising his work on the building bioclimatic chart by expanding the boundaries of the comfort zone with regards to people's' ability to acclimatize and adapt to a particular climatic condition under long exposure. 
PLANNING MALAYSIA

Journal of the Malaysia Institute of Planners (2015)

Sabarinah (2004), in reviewing thermal comfort zones for Malaysia based on local studies and other tropical countries in the region, summarises that comfort zones for Malaysia is between $25-30^{\circ} \mathrm{C}$ with $1.0-1.5 \mathrm{~m} / \mathrm{s}$ of wind, for naturally ventilated buildings. However, Hui (1998) previously found that urban wind speed rarely exceeds $1.0 \mathrm{~m} / \mathrm{s}$, and indoor wind speed is less than half of that. Therefore, natural ventilation strategies are not as reliable and ideal for the urban and suburban context. Even when houses face optimum orientation for wind, studies by Noor Aziah (2008) found poor correlation between orientations with internal temperature; and consequently, energy consumption too. However, the houses do experience comfort ventilation from prevailing wind but this is an unreliable means of achieving comfort. This finding enhanced the idea that the natural ventilation is no longer a feasible means for achieving comfort for terraced houses within the urban context.

\section{Building strategies}

From the analysis of the hot-humid climate characteristics and thermal comfort requirements, the architectural means that can help in providing comfort in unconditioned buildings must be climate-responsive. Particularly for hot-humid climates, the design of the building should aim at lowering the indoor temperatures and enabling effective natural ventilation to achieve thermal comfort. In order to facilitate this, the main design consideration is the orientation of buildings, which can influence the solar and thermal conditions and ventilation potentials. Appropriately orientated buildings have the potential to exclude any unwanted direct solar radiation which can elevate indoor temperatures while admitting prevailing winds whenever possible. Shading devices, location and sizing of windows and other openings should also be dependent on the orientation.

Another important feature that can maximize the orientation impact is the selection of building envelope materials (roofs, walls, and glazing) along with the shape and form of the building. According to Givoni (1998), the thermal properties of the building materials govern the relationship between the indoor average temperature and swing, and the corresponding outdoor air temperature pattern; influenced to a great extent by orientation. In the urban and suburban context of terraced houses, the use of insulation is most advantageous to modify the internal temperature in order to achieve and maintain comfortable temperatures over a wide range of external conditions. Even when it is not possible to achieve comfortable conditions, insulated walls and roofs will minimize discomfort or reduce energy consumption where heating or air conditioning is used (Evans, 1980). Ibrahim (1987) emphasizes that the use of insulation on both walls and roofs can significantly reduce internal temperature and will protect the roof from extreme temperature cycling and will thus prolong building life. His findings also suggest that walls facing west and east have a 
Noor Aziah Mohd Ariffin

Thermal Comfort And Energy Solutions For A Better Residential Environment In Malaysia

higher transmission value, and are, therefore, more critical and must be insulated to resist effects of solar radiation. Hence, the paper suggests investigating on both orientation and use of insulation parameters.

\section{RESEARCH METHOD EMPLOYED}

The method of research conducted sought to predict energy use and thermal comfort through computer simulation studies of hypothetical models. A model of an existing terraced house was simulated as the Base-Case (BC) study, and energy and thermal analyses undertaken to the performances. This was used as a benchmark for the Improvement (IMP) models: i.e. BC conditions with added passive design features. Comparative studies of the two models became basis for discussion and resulting recommendations for energy efficient design. The study uses the IES $\langle$ VE $>$ (Integrated Environmental Solutions <Virtual Environment $>$ ) program, which incorporated the validated powerful thermal analysis program ApacheSim. ApacheSim is linked with other suites of programs including SunCast, which analyses the shadowing impact of shading devices at different times of the day and year, and recalculates the energy output.

The aim of the investigation was to quantify the extent of energy and thermal performance due to varying orientation parameters on: firstly, a 'BaseCase' (BC) model using the conditions in an existing terraced house, and secondly on a series of Improvement (IMP) options where passive envelope features. The simulations were conducted for orientations from $0^{\circ}-350^{\circ}$ at $10^{\circ}$ intervals (36 orientations in all). The orientations were further divided into four different groups for reporting: NW-NE $\left(316^{\circ}-360^{\circ} \& 0^{\circ}-45^{\circ}\right)$; NE-SE $\left(46^{\circ}-135^{\circ}\right)$; SE-SW $\left(136^{\circ}-225^{\circ}\right)$ and SW-NW $\left(226^{\circ}-315^{\circ}\right)$.

\section{DATA ANALYSIS AND FINDINGS}

This section presents the results of simulation studies conducted on terraced houses of varying orientations, utilizing passive design features for the envelope configurations. The results will report on the extent of energy savings and thermal performance on both the BC and IMP models along with a cost analysis of the IMP options as compared to the $\mathrm{BC}$ model. The simulation runs generated annual energy consumption (AEC) data in $\mathrm{kWh}$ per year $(\mathrm{kWh} / \mathrm{yr})$ and the thermal performances in terms of indoor temperature.

\section{Base-Case (BC) Model Simulation}

Results of the BC simulation revealed the annual electricity consumption (AEC) of the modeled house, which was assumed to have a typical roof with no insulation [R1], $1 / 2$ brick thick walls with plaster on both sides [W1] and single clear float glazing [G1] for all windows and glazed doors. The abbreviation for the $\mathrm{BC}$ is [R1W1G1]. The findings revealed that the average energy consumption over all the orientations was $7,789 \mathrm{kWh} / \mathrm{yr}$. The highest energy consumption 
PLANNING MALAYSIA

Journal of the Malaysia Institute of Planners (2015)

occurred with the orientation of $100^{\circ}$ East at $7,948 \mathrm{kWh} / \mathrm{yr}$, within the NE-SE $\left(45^{\circ}-135^{\circ}\right)$ zone. Meanwhile, the lowest consumption occurred at the orientation of $340^{\circ}$ North at $7,606 \mathrm{kWh} / \mathrm{yr}$, within the NW-NE $\left(316^{\circ}-359^{\circ} \& 0^{\circ}-45^{\circ}\right)$ zone. The difference in AEC savings between the worst case (NE-SE) and the best case (NW-NE) scenarios translated to approximately $4.3 \%$ difference or $342 \mathrm{kWh} / \mathrm{yr}$ savings.

\section{Temperature Performance}

In terms of the temperature performance, similar findings were also established where rooms facing easterly show the highest temperature during the day and night, while northerly facing rooms have had the lowest. The average indoor temperatures for all the orientations were much higher than the average outdoor temperature, as revealed in Table 1. The predicted temperatures in the $\mathrm{BC}$ model for all four orientations revealed that average temperatures during the day exceeded the upper limit of thermal comfort of $30^{\circ} \mathrm{C}$ established for the Malaysian climate with more uncomfortable conditions in the east orientation.

Table 1: Thermal performances of the living room in the $\mathrm{BC}$ model during the peak outdoor conditions

\begin{tabular}{lccc}
\hline & \multicolumn{3}{c}{ Living } \\
\cline { 2 - 4 } & Max & Min & Ave \\
\hline NORTH & 33.4 & 28.5 & 30.7 \\
EAST & 35.1 & 29.5 & 32.6 \\
SOUTH & 33.3 & 28.7 & 31.0 \\
WEST & 34.0 & 28.5 & 30.9 \\
\hline Outdoor & 35.6 & 24.1 & 28.3 \\
\hline
\end{tabular}

\section{Improvement (IMP) Model Studies}

In order to improve the thermal comfort and reduce energy consumption of the $\mathrm{BC}$ model, the IMP model examined the effects of varying the improvements proposed on the $\mathrm{BC}$ model. The improvements used different thicknesses of insulation $(25 \mathrm{~mm}, 50 \mathrm{~mm}, 75 \mathrm{~mm}$ and $100 \mathrm{~mm}$ ) for the roof and wall, and different types of glazing (single and double). The IMP models were simulated in two steps: Step 1: INDV (individual) IMP investigated the energy performance of the different components individually - where one component was improved, and the two others remained, as shown in Table 2. 
Noor Aziah Mohd Ariffin

Thermal Comfort And Energy Solutions For A Better Residential Environment In Malaysia

Table 2: Simulation components for INDV IMP options

\begin{tabular}{llllll}
\hline & \multicolumn{4}{l}{ STEP 1: INDV IMP } \\
\cline { 2 - 6 } & \multicolumn{4}{l}{ Usage of insulation in 25mm thickness increment } \\
\cline { 2 - 6 } & BC $(0 \mathrm{~mm})$ & 25mm & $50 \mathrm{~mm}$ & $75 \mathrm{~mm}$ & $100 \mathrm{~mm}$ \\
\hline ROOF & R1 & R2 & R3 & R4 & R5 \\
WALL & W1 & W2 & W3 & W4 & \\
GLAZING & G1 (single) & G2 (double) & & \\
\hline
\end{tabular}

The series of permutations for the individual combinations for the 36 orientations gives a total of 324 simulation runs. The results of AEC from Step 1 eliminated several of the individual improvements options deemed inappropriate, and the remaining IMP options were combined further. In Step 2 the best performances from Step 1 were examined and the combined improvement (COMB IMP) options of all three components with different variations (see Table 3) were investigated further.

Table 3: Simulation components for the COMB IMP options

\begin{tabular}{llllll}
\hline \multicolumn{7}{c}{ STEP 2: COMB IMP } & & & \\
\cline { 2 - 6 } & BC $(0 \mathrm{~mm})$ & $25 \mathrm{~mm}$ & $50 \mathrm{~mm}$ & $75 \mathrm{~mm}$ & $100 \mathrm{~mm}$ \\
\hline ROOF & R1 & R2 & R3 & n.a & n.a \\
WALL & W1 & W2 & n.a & & \\
GLAZING & G1 (single) & G2 (double) & & & \\
\hline
\end{tabular}

Table 4 shows the series of the COMB IMP options undertaken to elicit the findings of this study.

Table 4: COMB IMP options undertaken

\begin{tabular}{|c|c|c|c|c|c|c|c|c|}
\hline \multicolumn{3}{|c|}{ ROOF1 } & \multicolumn{3}{|c|}{ ROOF2 } & \multicolumn{3}{|c|}{ ROOF3 } \\
\hline *R1 & $\mathrm{W} 1$ & G1 & R2 & W1 & G1 & R3 & W1 & G1 \\
\hline R1 & W1 & G2 & $\mathrm{R} 2$ & W1 & $\mathrm{G} 2$ & R3 & W1 & $\mathrm{G} 2$ \\
\hline R1 & W2 & G1 & R2 & W2 & G1 & R3 & W2 & G1 \\
\hline R1 & W2 & G2 & $\mathrm{R} 2$ & W2 & G2 & R3 & W2 & $\mathrm{G} 2$ \\
\hline
\end{tabular}

The COMB IMP option gives a total of 12 variations, resulting in a final total of 288 simulation permutations. Findings of the simulation results are discussed below. 


\section{Energy Performance}

Simulations of the AEC for the different COMB IMP revealed the option using [R3W2G2] or $50 \mathrm{~mm}$ insulation in the roof; $25 \mathrm{~mm}$ insulation in the walls and double-glazing presented the best AEC savings difference with the $\mathrm{BC}$ option. [R3W2G2] predicted an average AEC of $6,155 \mathrm{kWh} / \mathrm{yr}$, which is $1,634 \mathrm{kWh} / \mathrm{yr}$ less than the $\mathrm{BC}$ scenario. The optimum orientation is between $270^{\circ}$ and $320^{\circ}$ (W - NW). Although East orientations still show the highest consumption, after subjecting the figures to statistical analysis, the results show no significant differences among the AECs of all orientations. Therefore, utilizing [R3W2G2], suggested that the orientation parameters have no influence on the house's annual energy consumption. From the results, due to the improved strategies of utilizing insulation in the roof and walls, and double-glazing for windows the energy consumption differences between the terraced houses from all orientations is slight. The inference is that when terraced houses are protected, energy usage can be optimized: even for houses facing both east and west, which usually have a higher energy use.

\section{Temperature performance}

Similar to findings from the energy performance, simulations of the thermal performance also indicated that lowest temperatures are predicted for the option utilizing [R3W2G2]. Figure 2 summarizes the differences in temperatures among the design options when applied to each of the four orientations.

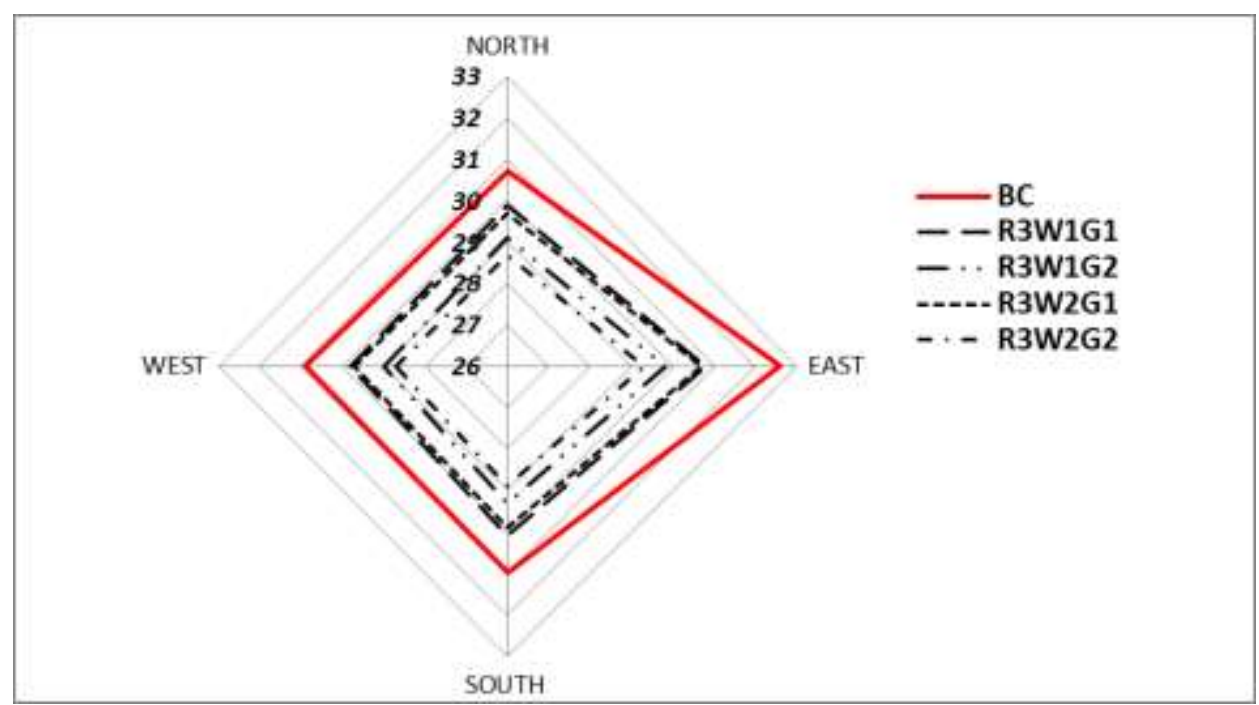

Figure 2: Differences in mean temperatures of the COMB IMP ROOF3 models at four different orientations with the $\mathrm{BC}$ 
Figure 2 indicates that the highest temperatures occurred in the east orientation as in previous analyses, with option [R3W2G2] showing the lowest temperatures among the four options. The graph also shows a distinct difference in thermal performance between utilizing walls with insulation [W2] and without insulation [W1], with the former showing better results. Figure 2 also shows the BC temperature performance profile, where the highest temperature difference between $\mathrm{BC}$ and the best COMB IMP [R3W2G2] is 2 to $3 \mathrm{~K}$, indicating better thermal performance for the improved options.

\section{Regression analysis}

Based on the simulations, the AEC data and optimum orientations were determined for the different IMP options. The next step was to provide a means for designers to use this data with simple mathematical calculation procedures to gauge the energy implications of orientation on their buildings.

A curvilinear regression analysis was performed to find the relationship between the AEC penalties as the dependent variable (y-axis) and the range of orientations from the optimum orientation as the independent variable ( $\mathrm{x}$-axis) for all the IMP options. From the analysis the best curve-fit regression line, is denoted by Equation 1. For this discussion, only the best results from the COMB IMP options will be used as examples, such as: [R1W2G2]; [R2W2G2] and [R3W2G2].

Equation 1: $\quad \mathrm{Y}=\mathrm{a}+\mathrm{b}_{1} \mathrm{x}_{1}+\mathrm{b}_{2} \mathrm{x}_{1}^{2}$

Where,

$$
\begin{aligned}
& \mathrm{Y}=\text { predicted or dependent variable } \\
& \mathrm{a}=\text { constant (slope) } \\
& \mathrm{X}=\text { independent variable (explanatory variable) } \\
& \mathrm{b}=\text { intercept of } \mathrm{X} \text {-axis on } \mathrm{y} \text {-axis }
\end{aligned}
$$

From the regression analysis, the mathematical equations for the three COMB IMP options selected are as follows:

For [R1W2G2];

Equation 2:

$$
\mathrm{y}=19.948+.767(\mathrm{x})+.22\left(\mathrm{x}^{2}\right)
$$

For [R2W2G2];

Equation 3:

$$
\mathrm{y}=22.471+1.063(\mathrm{x})+.233\left(\mathrm{x}^{2}\right)
$$

For [R3W2G2];

Equation 4:

$$
\mathrm{y}=4.25+.213(\mathrm{x})+.07\left(\mathrm{x}^{2}\right)
$$


Where, $(\mathrm{x})$ denotes each percentage of ranges $(5 \%, 10 \%, 15 \%$ or $20 \%)$, either clockwise or anticlockwise from the optimum orientation.

The equations are used to calculate the AEC penalties for the different COMB IMP options. The equations can help designers to predict energy consumption for the houses should they stray from the optimum orientation.

\section{Cost analysis}

A cost analysis was conducted to find out whether these improvements or modifications to the building would increase the required capital expenditure. The reason was to examine the relationship between having more energy efficient house and the capital expenditure of the required improvements. Whether or not the investment is prudent will be determined by discovering the period required to recover expenditure and to compare it to the cost of energy consumption in the improved models. Table 5 summarizes the cumulative cost impact of all the COMB IMP strategies on the original cost of the $\mathrm{BC}$, indicating the total capital expenditure and the recovery period in utilizing insulation and double-glazing in the COMB IMP options.

Table 5: Total investment costs and recovery period of investments of the COMB IMP options

\begin{tabular}{|c|c|c|c|c|c|c|c|c|c|c|}
\hline \multirow[t]{2}{*}{$\begin{array}{l}\text { Building } \\
\text { Component }\end{array}$} & \multicolumn{2}{|c|}{$\begin{array}{l}\text { Ave. Running } \\
\text { Cost/year }\end{array}$} & \multicolumn{3}{|c|}{ Actual savings } & \multicolumn{2}{|c|}{$\begin{array}{l}\text { Capital } \\
\text { expenditure } \\
(\mathrm{CP})\end{array}$} & \multicolumn{2}{|c|}{ Total CP } & \multirow[t]{2}{*}{$\begin{array}{l}\text { Recovery } \\
\text { Period* } \\
\text { (year) }\end{array}$} \\
\hline & MYR & $\mathrm{USD}^{* *}$ & MYR/yr & $\begin{array}{l}\text { USD/ } \\
\mathrm{yr}\end{array}$ & $(\%)$ & Insu. & Glaze & MYR & USD & \\
\hline R1W1G1 & 1947 & 617 & - & - & - & - & - & - & & - \\
\hline R3W1G1 & 1771 & 561 & 176 & 56 & 9.0 & 863.9 & - & 863.9 & 270 & 4.9 \\
\hline R3W1G2 & 1750 & 555 & 197 & 62 & 10.1 & 863.9 & 4076 & 4939.9 & 1566 & 25.1 \\
\hline R3W2G1 & 1676 & 531 & 271 & 86 & 13.9 & 1133.6 & - & 1133.6 & 359 & 4.2 \\
\hline R3W2G2 & 1539 & 488 & 408 & 129 & 21.0 & 1133.6 & 4076 & 5209.6 & 1652 & 12.8 \\
\hline
\end{tabular}

In the last column the recovery period of the capital investments is determined by the ratio between the total capital expenditure and the actual savings of the AEC, utilizing the different COMB IMP options. Generally, lower capital expenditures indicate a better internal rate of return (IRR) of investments in terms of the payback period (Gropelli \& Nikbakht, 2006), as in the case for [R3W1G1] and [R3W2G1] denoting recovery periods of 4.9 and 4.2 years, respectively. According to Table 5, assuming a cut-off rate or rate of return of $10 \%$ as acceptable (Gropelli \& Nikbakht, 2006), then the most profitable solution is option [R3W2G1] with a 14\% IRR and a payback period of 4.2 years. In another scenario option [R3W2G2] shows the highest IRR (21\%) and optimum thermal performance, but due to the higher capital investments where the payback period is 12.8 years, this option is seen as being less viable because it is not the most 
Noor Aziah Mohd Ariffin

Thermal Comfort And Energy Solutions For A Better Residential Environment In Malaysia

economical. The cost of providing the improvements would offset the house buyer by more than MYR5,200.00 (USD1,652).

To emphasize the viability of option [R3W2G1], the statistical analysis ANOVA was conducted between the temperatures of [R3W2G1] and [R3W2G2]. Although the findings indicate that there is significant difference between temperatures from the different orientations in both COMB IMP options $(\mathrm{p}=.032$ and $\mathrm{p}=.026$, respectively), in actual fact, the difference in mean temperatures for both options is less than $1 \mathrm{~K}$ between the highest (East) and the lowest figures (North). This suggests that [R3W2G1] is the most appropriate strategy (based on this study) to increase thermal comfort, and yet reduce energy consumption in a terraced house with an acceptable payback period on investment.

\section{CONCLUSION}

This study was conceived and conducted addressing the main contention that housing can be made more energy-efficient and more comfortable with appropriate passive design features: orientation and passive building material improvements to the building envelope. The study investigated the impact of orientation on indoor thermal conditions and energy consumption of mass medium-density terraced houses in Malaysia. The key issue stressed on the impact of orientation and building design factors upon thermal comfort and energy savings. The main outcomes from the parametric studies were the predicted annual energy consumption (AEC) and thermal performance of the modeled terraced units. The findings show that lower energy consumption and better thermal comfort is attainable with some improvements made to the existing terraced houses. The passive design strategies applied in this study predicted energy savings of about $20 \%$ from the base case (BC) scenario and indicated good potentials for the improvement of the residential environment. The findings of this study is beneficial to building designers in residential planning and design in terms of AEC should their designs stray from the optimum orientation. This study is in line with the 11th Malaysia Plan, where Malaysia's bid is to reduce energy consumption and carbon emissions in all sectors. The residential sector was found to be one of the intensive energy consumer and all efforts to mitigate this problem is pertinent. 
PLANNING MALAYSIA

Journal of the Malaysia Institute of Planners (2015)

\section{ACKNOWLEDGEMENTS}

The author would like to acknowledge with thanks the Research Management Centre, International Islamic University Malaysia, for partly funding this study.

\section{References}

Al-Obaidi, M.A.A.H. \& Woods, P. (2006). Investigations on effect of orientation on thermal comfort in terraced housing in Malaysia, International Journal of Low Carbon Technologies, 1 (2), 167-76.

ASHRAE (2010). Standard 55-2010: Thermal environmental conditions for human occupancy, American Society of Heating, Refrigerating and AirConditioning Engineers, Inc, Atlanta, GA. Retrieved from: http://www.ashraerp.com/files/ASHRAEStandard55-2013.pdf

Balce, G.R. \& Soriano, M.L. (1999). Energy efficiency practices and norms in buildings in ASEAN. Proposed Energy Efficiency \& Renewable Energy Provisions in the Uniform Building By-Laws. Kuala Lumpur.

Byrd, R.H. (2006). Energy, Ecology and Equality: a view of Malaysia after 2020 Penang: USM Publishing.

Davis, M.P., Shanmugavelu, S. \& Adam, N. (1997). Overheating in Malaysian houses. Affordable Quality Housing Seminar, Kuala Lumpur.

de Dear, R., Brager, G. \& Cooper, D. (1997). Developing an adaptive model of thermal comfort and preference. University of Macquarie: ASHRAE and Macquarie Research Ltd.

Department of Standards (2001). Malaysian Standard MS 1525 : 2001, Code of practice on energy efficiency and use of renewable Energy for nonresidential buildings.

Energy Commission Malaysia (2005). Building energy performance in Malaysia. EE Seminar - How to take advantage of it. Kuala Lumpur.

Evans, M. (1980). Housing, climate and comfort. London: Architectural Press Ltd.

Fanger, O. (1972). Thermal comfort. New York: McGraw-Hill Book Company.

Givoni, B. (1994). Passive and low energy cooling of buildings. New York: Van Nostrand Reinhold.

Givoni, B. (1998). Climate considerations in building and urban design. New York: Van Nostrand Reinhold.

Green Building Index (2009). Retrieved from www.greenbuildingindex.org

Gropelli, A.A. \& Nikbakht, E. (2006). Finance, 5th edition. New York: Barron's Educational Series.

Hui, S.K. (1998). Natural ventilation of low cost dwellings in the hot humid tropics of Malaysia. MA Architecture Thesis, Universiti Teknologi Malaysia.

Ibrahim, S.M.A. (1987). The thermal behavior of thermally insulated and uninsulated buildings. Energy. 12 (7), 615-22. 
Noor Aziah Mohd Ariffin

Thermal Comfort And Energy Solutions For A Better Residential Environment In Malaysia

ISO (2005). ISO 7730-2005: Ergonomics of the thermal environment - Analytical determination and interpretation of thermal comfort using calculation of the PMV and PPD indices and local thermal comfort criteria. Geneva: International Organization for Standardization.

Mohd Razali, A. (2002). The role of state and market in the Malaysian housing sector. Housing and the Built Environment, 17, 49-67.

National Property Information Centre (2014). Residential Property Stock Report lst Quarter 2014. Retrieved from: http://napic.jpph.gov.my/portal/content/Publication_PDF/q114residenti al.pdf

Nicol J.F. (2002). Why international thermal comfort standards don't fit tropical buildings. In Building Research and the Sustainability of the Built Environment in the Tropics, T.H. Karyono, F. Nicol \& S. Roaf, eds. Jakarta, Indonesia, 40.

Noor Aziah, M.A. (2008). Energy Efficient Design towards Energy Conservation for Terraced Housing in Malaysia, Phd Thesis, Curtin University of Technology, Western Australia

Nugroho, A.M., Mohd Hamdan, A. \& Ossen, D.R. (2007). A preliminary study of thermal comfort in Malaysia's single storey terraced houses. Journal of Asian Architecture and Building Engineering, 6 (1), 175-82.

Phoon, Z. (2004). Terrace houses still most popular. New Straits Times Malaysia, Property Times, 8 May 2004.

Sabarinah, S.A. (2004). A study on thermal comfort and energy performance or urban multistorey residential buildings in Malaysia, $\mathrm{PhD}$ Thesis, University of Queensland.

Saidur, R., Masjuki, H.H., Jamaluddin, M.Y. \& Ahmed, S. (2007). Energy and associated greenhouse gas emissions from household appliances in Malaysia. Energy Policy, 35 (3), 1648-57.

Torii, T. (2003). The mechanism for state-led creation of Malaysia's middle classes. The Developing Economies, XLI (2), 221-42. 